\title{
Pemaknaan dan Transmisi Mantra Tri Sandhya Pada Remaja Hindu Bali di Daerah Malang
}

\author{
Khairul Candra, Luh Putu Ema Noviyanti, Kiki Nurlaily \\ Fakultas Keguruan dan Ilmu Pendidikan Universitas Muhammadiyah Malang \\ khairulchandra1@gmail.com
}

\begin{abstract}
Abstrak
Tulisan ini mengulas mengenai makna dan transmisi mantra Tri Sandhya. Mantra Tri Sandhya merupakan salah satu bentuk sastra lisan yang ada di Bali. Mantra Tri Sandhya merupakan mantra yang dimiliki oleh umat Hindu Bali yang digunakan dalam kehidupan sehari-hari. Pada saat ini, mantra Tri Sandya mulai dilupakan dan jarang digunakan oleh remaja Hindu Bali. Berdasarkan latar belakang tersebut, penelitian ini dilakukan untuk (1) mengetahui makna mantra Tri Sandhya: (2) transmisi mantra Tri Sandhya pada remaja Hindu Bali yang tinggal di Malang. Metode yang digunakan dalam penelitian ini adalah metode deskriptif kualitatif. Metode yang digunakan dalam penelitian ini untuk memperoleh data dalam bentuk kalimat bukan angka-angka. Sumber data dari penelitian ini adalah Mantra Tri Sandhya. Penelitian ini menggunakan pendekatan Semiotika dengan teori Riffaterre. Semiotika digunakan untuk mengkaji tanda-tanda yang ada dalam mantra Tri Sandhya sehingga pembaca dapat memahami makna dari mantra Tri Sandhya. Hasil penelitian ini menunjukkan bahwa makna mantra Tri Sandhya dan transmisi mantra Tri Sandhya pada remaja Hindu Bali di wilayah Malang saat ini.
\end{abstract}

Kata kunci : makna; transmisi; mantra Tri Sandhya; semiotika

\begin{abstract}
This paper reviews the meaning and transmission of Tri sandhya mantra.Mantra Tri Sandhya is one form of oral literature in Bali. Mantra Tri Sandhya is a mantra owned by Balinese Hindus used in everyday life. At this moment, the Tri Sandya spell is being forgotten and rarely used by Balinese Hindu teenagers. Based on this background, this study was conducted to (1) know the meaning of Tri Sandhya mantra: (2) Tri Sandhya spell transmission on Balinese Hindu adolescents living in Malang. The method used in this research is descriptive qualitative method. The method used in this study to obtain data in the form of sentences instead of numbers. The data source of this research is Mantra Tri Sandhya. This research uses Semiotics approach with Riffaterre theory. Semiotics is used to examine the signs that exist in the Tri Sandhya spell so readers can understand the meaning of the Tri Sandhya spell. The results of this study indicate that the meaning of Tri Sandhya mantra and Tri Sandhya spell transmission on Balinese Hindu adolescents in Malang region today.
\end{abstract}

Keywords: meaning; transmission; Tri Sandhya; semiotics

\section{Pendahuluan}

Indonesia adalah negara yang kaya akan kebudayaan. Salah satu kebudayaan daerah yang dimiliki Indonesia yaitu berupa sastra lisan. Sastra lisan pada beberapa daerah di Indonesia sampai sekarang masih tetap dimanfaatkan dan dilestarikan. Faktanya sampai sekarang masih ada masyarakat di beberapa daerah yang masih melestarikannya. Sastra lisan merupakan salah satu bentuk kebudayaan yang harus kita jaga dan terus dilestarikan. Menurut Zulfadhli (2010: 61) sastra lisan merupakan warisan budaya masyarakat kare- 
na di dalamnya tercermin pikiran, perasaan, dan cita-cita masyarakat pendukungnya. Oleh karena itu sastra lisan tidak dapat dipisahkan dari kehidupan atau kebudayaan suatu masyarakat.

Realitasnya pada saat ini sastra lisan sudah sulit ditemui. Hal ini disebabkan proses penyebarannya dilakukan secara lisan serta menggunakan bahasa daerah, sehingga akibatnya generasi penerus yang tidak memahami bahasa daerah menjadi tidak mengenal kebudayaan tersebut. Faktor inilah yang dapat mengakibatkan budaya-budaya daerah mulai hilang secara perlahan, karena yang memahaminya hanya orang-orang tertentu saja.

Sastra lisan dianggap sebagai suatu warisan budaya daerah yang turun temurun berkembang dalam lingkungan masyarakat. Sastra lisan merupakan pembedaharaan nilai-nilai yang diwariskan dari generasi ke genarasi. Nilainilai yang terkandung dalam sastra lisan masih sangat berguna pada masa sekarang (Wakisti, 2011:1093). Pada dasarnya budaya memiliki nilai -nilai yang selalu diwariskan, ditafsirkan dan dilaksanakan seiring dengan perubahan proses sosial kemasyarakatan. Pelaksanaan nilai-nilai budaya merupakan bentuk penghargaan masyarakat terhadap kebudayaan yang dimiliki.

Menurut Sudewa (2014: 66) kehidupan sastra lisan banyak mengalami pasang surut. Pada mulanya, sastra lisan yang berkembang di masyarakat Bali khususnya yang ada di daerah perdesaan masih sangat kuat, namun pada saat ini kebudayaan sastra lisan tersebut mulai terlupakan. Hal ini disebabkan karena pertumbuhan dan perkembangan teknologi yang mod- ern dan banyaknya penduduk pedesaan yang mulai pergi merantau ke kota. Pengaruh perkembangan zaman dan era globalisasididuga menjadi salah satu penyebab Kebudayaan Bali secara terus menerus mendapat tekanan dan pengaruh terhadap eksistensi kebudayaannya.

Salah satu bentuk sastra lisan berupa puisi magis atau mantra. Menurut Medan (dalam Amir, 2013:68-69) mantra adalah bagian dari kesusastraan lama karena mengandung unsur emosional, unsur keindahan berupa irama dan unsur nilai moral karena mantra adalah asimilasi antara bahasa dan kepercayaan. Kebudayaan berupa sastra lisan memiliki suatu nilai tertentu. Nilai-nilai budaya dan sastra tersebut diciptakan dan diwariskan secara turun temurun oleh nenek moyang kepada masyarakat sampai masa modern (Nurjamilah, 2015:123). Jika mantra diwariskan kepada orang terpilih, biasanya ditandai dengan adanya firasat tertentu atau wangsit untuk mewariskannya pada orang lain. Manfaat dan kegunaan dari mantra antara lain untuk mengusir musibah, mengobati orang sakit, penarik cinta, melindungi diri dan lain sebagainya.

Tabanan merupakan salah satu daerah di Bali yang masih melestarikan sastra lisan berupa mantra. Tabanan merupakan salah satu kabupaten yang berada di Provinsi Bali Indonesia. Terletak sekitar $35 \mathrm{~km}$ di sebelah barat Kota Denpasar. Tabanan berbatasan dengan Kabupaten Buleleng di sebelah utara, Kabupaten Badung di sebelah timur, Samudra Indonesia di selatan dan Kabupaten Jembrana di sebelah barat. Kebanyakan penduduk di sana mayoritas beragama Hindu. Menurut Hasse (2012: 339) agama Hindu yaitu agama yang pal- 
ing luwes di antara agama-agama yang lainnya karena tidak ada aturan yang menyamai seluruh sekte yang ada di dalam ajaran Hindu. Secara historis kultur yang dibangun di Bali lebih dominan ada dalam pengaruh agama Hindu. Sehingga setiap berbicara mengenai Bali, maka akan selalu identik dengan agama Hindu, bahkan kemudian Bali dikenal sebagai Hindu Dharma, artinya perilaku keberagamaan lebih dominan ada dalam tradisi kehinduan (Miharja, 2013: 55).

Salah satu bentuk sastra lisan Bali yang mengalami kemunduran adalah mantra $T r i$ Sandhya. Kemunduran di sini diartikan banyak masyarakat yang mulai melupakan makna atau arti dari mantra tersebut. Bahkan adapula yang sama sekali tidak mengetahui makna dari mantra Tri Sandbya. Mantra Tri Sandhya merupakan mantra yang wajib dihafal dan dipahami maknanya bagi umat Hindu. Mantra ini wajib dilakukan oleh umat Hindu pada saat melakukan sembahyangan. Melakukan sembah bakti atau puja sembah Tri Sandbya bisa dilakukan di mana saja dan dalam kondisi apapun. Mantra Tri Sandhya juga dapat diucapkan dalam posisi sedang tidur, berdiri, duduk dan sebagainya, baik itu dilakukan di dalam rumah, di merajan atau tempat suci yang ada di rumah, di pura, di sekolah, ataupun dimana saja. Menurut (Tim Penyunting,1998: 9) Sembahyang yang dilakukan setiap tiga kali sehari yaitu untuk memuja dan memuji kemuliaan-Nya serta kita menundukan diri sebagai rasa bakti kehadapan Sang Hyang Widhi Wasa atau Tuhan Yang Maha Esa dengan tujuan untuk menyatakan rasa terima kasih atas segala ciptaan-Nya yang telah kita nik- mati.

Melihat dari penjelasan tersebut, maka permasalah yang akan diteliti adalah bagaimana makna yang terkandung dalam mantra Tri Sandhya, Serta mengapa remaja Hindu Bali yang berada di daerah Malang mulai melupakan makna dan transmisi mantra Tri Sandhya yang menjadi salah satu kebudayaan khas yang mereka miliki dan seharusnya mereka lestarikan. Penelitian mengenai makna dan transmisi mantra Tri Sandhya ini belum pernah dilakukan sebelumnya. Sehingga penelitian ini penting untuk dilakukan. Penelitian ini penting dilakukan untuk mendeskripsikan dan mengungkapkan makna yang terdapat pada mantra Tri Sandhya serta bagaimana hasil transmisi mantra Tri Sandhya pada generasi penerusnya yang bera di daerah Malang pada saat ini.

Penelitian ini menggunakan pendekatan semiotik menurut teori Riffaterre dan teori transmisi menurut Albert Lord. Menurut Riffaterre (dalam Ardiansyah, 2017:174) proses semiotik sebenarnya terjadi dalam pikiran pembaca. Menggunakan teori riffaterre pembaca dapat mengenali aspek kebahasaan yang terdapat dalam puisi menggunakan kemampuan kesastraan yang dimiliki dan memungkinkannya untuk menemukan tanda dalam puisi tersebut. Semiotik menganggap bahwa fenomena sosial atau masyarakat dan kebudayaan di dalamnya merupakan tanda-tanda. Semiotik juga mempelajari sistem -sistem, atauran-aturan yang memungkinkan tanda -tanda tersebut mempunyai arti (Agustina, 2017:55). Sedangkan menurut Albert Lord dalam saputra (2010: 163-164) transmisi ialah proses untuk mempelajari, menyusun dan menampilkan 
suatu karya secara lisan merupakan bentuk rangkaian kelisanan yang diorientasikan pada suatu proses tertentu.

\section{Kajian pustaka}

Penelitian ini menggunakan Pendekatan Semiotika dengan teorinya Riffaterre dan teori transmisi yang dikemukakan oleh Albert Lord. Semiotik adalah ilmu yang membahas mengenai tanda-tanda. Dalam bahasa Yunani Kuno, semiotik yaitu 'semeion' yang berarti tanda dan dalam bahasa Inggris, yaitu 'sign'. Menurut Pradopo yang dikutip dari Preminger (1999:76) menyatakan bahwa semiotika, ilmu yang mengkaji tentang tanda-tanda, mempelajari fenomena sosialbudaya, termasuk sastra sebagai sistem tanda. Tanda mempunyai dua aspek, yaitu penanda (signifie, signifiant) dan petanda (signified, signifie). Saussure menjelaskan 'tanda' sebagai kesatuan yang tak dapat dipisahkan dari dua bidang, seperti halnya selembar kertas yaitu bidang penanda (signifier) untuk menjelaskan 'bentuk' atau 'ekspresi' dan bidang petanda (signified) untuk menjelaskan 'konsep' atau 'makna' (Piliang, 2004:191).

Semiotika menurut Tinarbuko (2003:3334) adalah ilmu yang mempelajari tentang tanda. Tanda-tanda tersebut menyampaikan suatu informasi sehingga bersifat komunikatif. Manusia hanya dapat berkomunikasi lewat sarana tanda. Tanda dalam kehidupan manusia bisa tanda gerak atau isyarat. Tanda tulisan, di antaranya huruf dan angka. Ambarini yang dikutip dari Riffatere (Teeuw, 1983;65) mengatakan bahwa pembaca yang bertugas memberi makna pada sebuah karya sastra, harus memulai dengan menemukan meaning unsur-unsurnya berupa kata menurut kemampuan bahasa yang berdasarkan fungsi bahasa sebagai alat komunikasi tentang gejala di dunia luar.

Penggunaan Pendekatan Semiotika dalam pengkajian mantra Tri Sandhya yaitu untuk megetahui tentang tanda-tanda dalam pemakain bahasa lisan yang digunakan. Tujuan dari pendekatan ini adalah untuk mengungkapkan makna yang terdapat dalam mantra tersebut. Jika didengar secara sekilas bahasa mentra memang kelihatan tidak memiliki makna yang logis tetapi jika dipahami secara mendalam mantra memiliki makna yang sangat kental dengan unsur gaib atau magis. Mantra ini bersifat abstrak yang disampaikan secara lisan kepada penerusnya, jadi tak heran jika mantra ini tidak semua orang bisa menguasainya apalagi mengetahui maknanya.

\section{Metode}

Metode penelitian merupakan hal terpenting yang diperlukan dalam sebuah penelitian. Metode merupakan suatu cara yang digunakan peneliti untuk mengkaji objek penelitiannya (Nyoman, 2015:34). Metode penelitian berfungsi untuk mengarahkan penelitian yang dilakukan agar sesuai dengan tujuan yang diinginkan. Metode yang dilakukan dalam penelitian ini adalah metode deskriptif kualitatif. Metode ini digunakan karena ketika meneliti data yang digunakan berupa kalimat-kalimat bukan angka-angka. Penelitian kualitiatif digunakan untuk mendapatkan data-data keterangan yang jelas dan faktual menegenai makna dan transmisi mantra Tri Sandhya. 
Poetika : Jurnal Ilmu Sastra

Vol. VI No. 1 Juli 2018
DOI $10.22146 /$ poetika.35679

ISSN 2338-5383 (print) ; 2503-4642 (online)
Metode deskriptif merupakan suatu cara yang digunakan untuk memecahkan masalah dengan mengambarkan keadaan objek penelitian yang berupa (mantra, puisi, novel, cerpen dll) berdasarkan dengan keadaan atau fakta-fakta yang ada pada saat ini. Sumber data dari penelitian ini yaitu

1. I Nyoman Natar yang merupakan penuturan mantra Tri Sandhya di Dusun Dajan Peken, Desa Timpag, Kecamatan Kerambitan, Kabupaten Tabanan, Bali.

2. Ni Made Emi Noviyani Mahasiswi Universitas Muhammadiyah Malang.

3. Ni Luh Putu Valerian Ardensia Mahasiswi Universitas Muhammadiyah Malang

4. I Gede Putu Sinatrya Dewantara Manohara Mahasiswa Universitas $\mathrm{Mu}-$ hammadiyah Malang.

Dalam hal ini penutur mantra adalah seorang pemeluk asli agama Hindu Bali dari kasta Sudra.

Teknik pengumpulan data penelitian ini menggunakan beberapa cara. Yaitu :

1. Perekaman

Teknik perekaman digunakan peneliti untuk merekam mantra Tri Sandhya yang dituturkan oleh penuturnya sebagai data utama penelitian ini.

2. Wawancara

Peneliti melakukan wawancara untuk memperoleh data yang lengkap mengenai struktur, makna, isi dan transmisi mantra Tri Sandhya sesuai dengan penelitian ini dilakukan. Wa- wancara adalah proses tanya jawab lisan di mana dua orang atau lebih bertatap muka secara fisik untuk mengetahui pendapat seseorang terhadap suatu objek (Soegijono,1993: 18).

Teknik analisis data yang dalam penelitian ini menggunakan beberapa teknik yaitu teknik transliterasi (penerjemahan bahasa mantra ke bahasa Indonesia), kemudian dilanjutkan dengan memilah-milah data sesuai dengan kelompoknya, kemudian dianalisis dan ditarik kesimpulan.

Tahap-tahap analisis data :

1. Menuliskan kembali mantra yang sudah direkam untuk memepermudah dalam menganalisis.

2. Menerjemahkan bahasa dalam mantra Hindu Bali ke dalam bahasa Indonesia.

3. Membaca kembali mantra yang telah ditulis.

4. Menulis data mantra.

5. Menguraikan makna mantra.

6. Menarik kesimpulan.

\section{Hasil dan pemhahasan}

Penelitian ini dilakukan untuk mengkaji makna dan transmisi mantra Tri Sandhya. Pengkajian ini dilakukan untuk mengetahui bagaimana sebenarnya makna dari mantra tersebut, serta bagaimana penurunan mantra tersebut pada generasinya saat ini yang berada di daerah Malang, dengan keadaan zaman yang semakin hari semakin berkembang dan semakin modern. Kajian semiotik yang dilakukan terhadap mantra sembahyang umat Hindu adalah salah satu bentuk usaha untuk menumbuhkan kesadaran bagi pem- 
ilik mantra tersebut. Dalam hal ini pengkajian terhadap mantra Tri Sandhya dilakukan menggunakan teori semiotika Riffaterre. Bertolak pada teori semiotik Riffaterre maka peneliti dalam mengartikan makna mantra Tri Sandbya dengan melakukan pembacaan secara hermeneutika terhadap mantra milik umat Hindu Bali. Langkah tersebut dilakukan untuk mendeskripsikan makna mantra Tri Sandhya secara keseluruhan, sehingga menghasilkan suatu makna yang tepat. Analisis akan dilakukan dengan data penelitian berupa mantra Tri Sandhya yang merupakan mantra sembahyang umat Hindu. Berikut akan dilakukan pengkajian mengenai mantra Tri Sandhya dengan teori semiotika Riffaterre.

\section{Makna Mantra Tri Sandhya}

\section{Pemahaman Makna Mantra Tri Sandhya Menurut Pembaca}

Mantra Tri Sandhya dikenal sebagai ibu dari semua mantra umat Hindu. Umat Hindu Bali biasanya menyebutnya dengan sebutan $\mathrm{Pu}-$ ja Tri Sandbya. Mantra Tri Sandbya terdiri dari enam bait. Pada dasarnya mantra Tri Sandbya memiliki fungsi bagi seorang hamba yaitu untuk memohon ampunan atas semua dosa-dosa yang telah dilakukan di dunia ini (merca pade). Kemudian diwujudkan dalam bentuk permohonan kepada Tuhan Sang Hyang Widhi melalui perantara dewa dan dewi. Dewa dan Dewi yang disebutkan dalam mantra Tri Sandhya adalah Dewa Siwa, Brahma, Rudra, Mahadewa, Wisnu, Narayana, Bhur, Bhuva svah dan Purusa. Melalui pembacaan dan pemahaman pembaca dapat mengerti lebih dalam mengenai makna mantra Tri Sandhya. Berikut adalah pengkajian atau pemaknaan mantra Tri Sandhya:

\section{Om bhur bhuvah svah \\ Tat savitur verenyam \\ Bhargo devasya dhimahi \\ Dhiyo yo nah pracodayat}

Arti dari mantra bait pertama yaitu $O m$ (Tuhan) adalah Bhur Bhuva Svah. Kita memusatkan pikiran dan kecermelangan dan kemuliaan Sang Hyang Widhi, semoga diberikan semangat pada pikiran kita.

Mantra pada bagian ini memiliki makna sesungguhanya seorang hamba selalu mengingat Tuhan Sang Hyang Widhi yaitu Tuhan semesta alam. Sebagai seorang hamba sebaiknya selalu mengingat Tuhannya dengan memusatkan pikiran hanya kepada-Nya, semoga selalu diberikan semangat oleh Tuhan Sang Hyang Widhi. Dengan semangat tersebut seorang hamba akan memperoleh kecermelangan dan kemuliaan di hadapan Tuhannya. Sasaran dari mantra bait pertama adalah kecemerlangan dan semangat yang diberikan oleh Tuhan Sang Hyang Widhi pada hamba-Nya. Tujuan dari bait ini meminta agar Tuhan Sang Hyang Widhi memberikan semangat pada hambaNya dengan cara memusatkan pikiran pada kecemerlangan dan kemuliaan Tuhan.

\section{Om narayana everdwam Yad bhutam yac ca bhavyam Nirvikalpo nirakbyatah Suddho deva eko} Narayana na dvitiyo asti kescit

Arti dari mantra bait kedua adalah $\mathrm{Om}$ narayana, apa yang akan ada di alam semesta ini, terbebas dari noda, dari kotoran, dari perubahan tak dapat digambarkan dan sucilah Dewa Naraya- 
Poetika : Jurnal Ilmu Sastra

Vol. VI No. 1 Juli 2018
DOI 10.22146/poetika.35679

ISSN 2338-5383 (print) ; 2503-4642 (online) na. Ia hanya satu tidak ada yang kedua.

Pada bait ini memiliki makna yang menggambarkan bahwa Tuhan Narayana adalah Esa tidak ada yang kedua, disebut pula bahwa Narayana adalah Tuhan yang maha suci, maha cemerlang, tidak berwujud dan gaib. Umat Hindu mempercayai bahwa Narayana adalah sosok Tuhan yang maha suci yang keberadaannya setara dengan dewa-dewa yang lain.

\section{Om tvam siwah tvam mahadevah Iswarah paramesvarah Brabma visnusca rudrasca Purusah parikirtitah}

Arti dari bait ketiga adalah $\mathrm{Om}(\mathrm{Ya} \mathrm{Tu}-$ han Engkau dipanggil Siwa yang maha pengasih dan penyayang, maha dewa, [Engkau, Tuhan] yang kuasa dan yang tertinggi, Brahma yang menciptakan, Wisnu yang bekerja, dan Rudra dipanggil juga sebagai Purusqa jiwa alam semesta).

Makna dari bait ke tiga yaitu Umat Hindu Bali menyebutkan nama Tuhan mereka dengan berbagai nama sesuai dengan perwujudan Tuhan mereka, ada yang disebut Dewa Siwa, Wisnu, Brahma, Narayana, dll. Tuhan dalam agama Hindu adalah Sang Hyang Widhi, Ia tunggal tetapi banyak nama Tuhan yang digunakan untuk menunjuk pada satu Tuhan yaitu Hyang Widhi. Maksudnya ialah umat Hindu hanya memiliki satu Tuhan akan tetapi mereka memiliki banyak nama untuk menyebut Tuhannya.

Om papo'ham papakarmaham

Papatma papasambhavah

Trabi mam pundarikaksa

Sababybhyantarah sucib
Arti dari bait keempat adalah Oh Hyang Widhi Wasa, hamba ini papa, lemah. Jiwa Hamba papa dan kelahiran hambapun papa. Hendaklah Engkau melindungi hamba yang papa ini. Sang Hayng Widi. Sucikanlah jiwa dan raga hamba lahir dan batin.

Pada bait ke empat memiliki makna adanya pengakuan diri seorang hamba Tuhan terhadap dirinya. Begitu lemahnya Ia di hadapan Tuhan. Seorang hamba mengatakan bahwa dirinya hina, serba kurang dan lemah. Hina kerjanya, hina diri pribadinya, hina lahirnya karena itulah dia memohon kepada Tuhan agar dilindungi dan dibersihkan dari segala noda. Tuhan sebagai pelindung tertinggi dan Tuhan melimpahkan kesucian untuknya yang setia mengamalkan ajaran-Nya.

\section{Om Ksamasva mam mahadeva Sarvaprani bitankara Mam moca sarva papebhyah Palayasva ada siva}

Arti dari bait kelima adalah Oh Tuhan ampunilah hamba, Sanghyang Widhi, yang Memberikan kebahagiaan kepada semua makhluk. Bebaskanlah hamba dari segala dosa. Lingdungilah oh Sang Hyang Widhi (Siwa).

Pada bait ke lima memiliki makna bahwa Seorang hamba memohon ampunan kepada Tuhannya sebagai penyelamat semua makhluk, dia memohon dibebaskan dari semua papa, semua kehinaan dan dosa. Dia memohon agar dijaga karena hanya Tuhanlah penjaga semua makhluk di mana pun dan kapan pun. Tuhan adalah kuasa tertinggi atas segala yang ada di dunia ini.

Om ksantavyah kayiko dosah

Ksantavyo, vaciko mama

Ksantavyo manaso dosah 
Poetika : Jurnal Ilmu Sastra

Vol. VI No. 1 Juli 2018
DOI $10.22146 /$ poetika.35679

ISSN 2338-5383 (print) ; 2503-4642 (online)
Tat pramadat ksamasva mam

Om santih, santih, santih om

Arti dari bait keenam adalah Ya Tuhan, ampunilah dosa anggota badan hamba. Ampunilah dosa perkataan hamba. Ampunilah dosa pikiran hamba. Ampunilah hamba dari kelalalian hamba, semoga damai, damai, damai ya Tuhan.

Pada bait keenam memiliki makna apa saja dosa yang telah dilakukan oleh anggota badan, apa saja dosa kata-kata dan pikiran, seorang hamba memohon kepada Tuhannya untuk diampuni. Manusia tidak bisa terbabas dari kekhilafan dan kelalaian. Apabila sesorang dapat membersihkan diri dengan kebaikan maka kekhilafan seorang hamba akan berkurang dan memancarkan cahaya kesucian dari sang pribadi yang mengatur seseorang ke dalam alam kesadaran.

Pada hakikatnya umat Hindu Bali memiliki cara tersendiri untuk melakukan sembahyang. Sembahyang tersebut dilakukan untuk menyerahkan diri pada kekuatan Sang Hyang Widhi (Tuhan). Secara tidak langsung segala tata cara sembahyang yang dilakukan umat Hindu Bali memiliki sejarah masing-masing. Makna mantra Tri Sandhya adalah permohonan ampunan bagi pemeluk agama Hindu, perlindungan dan bentuk pengakuan diri seorang hamba yang lemah. Tujuan dari mantra ini adalah memohon ampunan yang diminta secara lahir dan batin agar Tuhan mengampuni segala dosa yang telah dilakukan. Agar seorang hamba kembali suci.

Mantra Tri Sandhya merupakan sebuah doa yang ditujukan kepada Tuhan untuk menunjukkan bahwa seorang hamba membutuhkan Tuhan. Hanya Tuhanlah yang bisa mengampuni semua dosa yang telah diperbuat. Mantra ini ialah wujud dari kepasrahan seorang hamba pada setiap hal yang sudah ditakdirkan kepada setiap hamba yang beragama.

\section{Transmisi Mantra Tri Sandhya Pada} Remaja Hindu Bali di Daerah Malang

Menurut KBBI yang diakses secara online, kata transmisi memiliki arti pengirim (penerusan) pesan dari seseorang kepada orang lain, sedangkan mentransmisikan berarti mengirimkan atau meneruskan pesan dari seseorang kepada orang lain. Sehingga transmisi juga dapat diartikan sebagai penurunan atau pewarisan.

Kunci utama dari keberhasilan sebuah proses transmisi sebuah kebudayaan terletak pada bagaimana para generasi penerusnya dalam menjaga kebudayaan yang mereka miliki. Apabila mereka tidak melestarikan kebudayaan yang mereka miliki, maka dalam penurunan kebudayaannya akan hilang secara perlahan seiring dengan perkembangan zaman yang semakin modern.

Sebuah mantra biasanya selalu ditransmisikan pada generasi berikutnya. Hal tersebut dimaksudkan untuk menjaga kelestarian kebudayaan yang mereka miliki serta agar kebudayaan itu tetap digunakan untuk generasi berikutnya. Dalam penurunannya mantra biasanya memiliki suatu persyaratan tertentu dan kepada sebuah golongan tertentu.

Pewarisan mantra Tri Sandhya di Dusun Dajan Peken, Desa Timpag, Kecamatan Kerambitan, Kabupaten Tabanan, Bali bersifat turun 
temurun atau diwariskan dari generasi ke generasi. Pewarisan mantra Tri Sandhya tidak dilakukan berdasarkan pembagian kelompok atau keluarga tertentu. Menurut Informan pertama yaitu bapak Nyoman "pewarisannya diberikan kepada semua generasi umat Hindu sejak mereka berusia empat tahun atau ketika mereka mulai menginjak bangku sekolah". Pembelajaran mengenai mantra Tri Sandhya pertama kali dilakukan di bangku sekolah yang dilakukan oleh guru. Dengan cara mengajari perkata dan mempraktekkan gerakannya, kemudian para siswa diminta untuk menirukannya. Pembelajaran tersebut dilakukan secara terus menerus hingga mereka dapat memahami mantra dan menirukan mantra Tri Sandbya yang menjadi mantra wajib yang harus mereka ketahui dan mereka amalkan dalam kehidupan sehari-hari.

Masyarakat Bali membiasakan untuk menerapkan menggunakan mantra Tri Sandbya dalam kehidupan sehari-harinya. Seiring perkembangan zaman, pada saat mereka sudah menginjak masa remaja dan tidak sedikit yang mulai merantau keluar daerah untuk mencari ilmu. Mereka mulai melupakan kebudayaan yang mereka miliki, salah satunya mantra Tri Sandhya. Sebagian dari mereka tidak menggunakan mantra Tri Sandhya dalam kehidupan sehari-harinya. Bahkan banyak pula yang tidak mengetahui makna dari mantra Tri Sandhya tersebut.

Menurut wawancara yang telah dilakukan dengan tiga remaja Hindu Bali yang berada di daerah Malang mereka memiliki beberapa pendapat sehingga dapat ditarik kesimpulkan bahwa proses transmisi tersebut mulai sulit dil- akukan karena beberapa faktor :

1) Kurangnya pengetahuan mengenai makna mantra.

2) Kurangnya pemahaman pentingnya manfaat dari mantra tersebut.

3) Kurangnya kesadaran dari tiap individu untuk mengamalkan mantra.

4) Karena faktor lingkungan juga dapat mempengaruhi pola hidup mereka.

Tanggapan para remaja Hindu saat ini:

Tanggapan Informan 1

Tanggapan Informan 2

Tanggapan Informan 3

Sebagai remaja Hindu Bali memang seharusnya kami berperan untuk menjaga kelestarian kebudayaan yang kami miliki. Namun, pada saat ini kebanyakan dari remaja Bali yang mulai melupakan mantra Tri Sandhya. Apabila peristiwa seperti ini terus dibiarkan terjadi maka kebudayaan sastra lisan berupa mantra Tri Sandhya milik umat Hindu Bali akan terlupakan baik dari kegunaan dan fungsinya seiring dengan perkembangan jaman yang seakin modern.

Cara yang digunakan untuk menyelamatkan kebudayaan mantra Tri Sandhya:

Menurut Informan 1

Menurut Informan 2

Menurut Informan 3

Langkah pertama yang dapat dilakukan untuk menyelamatkan mantra Tri Sandhya yaitu dengan menumbuhkan kesadaran pada pola berpikir remaja Hindu Bali mengenai betapa pentingnya pengamalan dan pemanfaatan mantra Tri Sandhya bagi kehidupan mereka. Langkah kedua 
dengan memberikan pengetahuan pada mereka mengenai makna mantra Tri Sandhya sehingga dengan mengetahui makna mantra tersebut mungkin dapat menumbuhkan kesadaran diri mereka untuk menjaga transmisi mantra dan menjalankannya sebagaimana yang telah diajarkan sewaktu masih kecil.

\section{Kesimpulan}

Semiotik pada dasarnya ialah ilmu yang digunakan untuk mengkaji sebuah tanda. Sebuah tanda yang dimaksud ialah tanda yang terdapat dalam sebuah karya, tanda tersebut berupa penggunaan lambang-lambang bahasa yang dapat ditafsirkan dan memiliki suatu makna. Dalam mengkaji mantra Tri Sandhya semiotika sangat diperlukan untuk mengetahui makna dan kandungan dari mantra tersebut, karena mantra tersebut menggunakan bahasa sansekerta.

Melalui pendekatan semiotik dalam mengkaji mantra tersebut dapat ditarik kesimpulan bahwa banyak mantra sembahyang yang dipakai oleh umat Hindu Bali untuk memuja Tuhannya. Mantra Tri Sandhya adalah ibu dari semua mantra tersebut serta mantra Tri Sandhya selalu digunakan dalam setiap upacara ritual yang dilaksanakan umat Hindu di Bali. Mantra Tri Sandhya digunakan dalam melakukan sembahyang sebanyak tiga kali dalam satu hari yaitu pada pukul 06:00, pukul 12:00 dan pukul 18.00 .

Mantra Tri Sandhya adalah mantra yang digunakan umat Hindu untuk memohon ampunan dan perlindungan pada Tuhan mereka sebagai suatu bentuk pengakuan bahwa mereka adalah hamba yang lemah. Tujuan dari pembacaan mantra ini adalah agar permohonan ampunan seorang hamba dikabulkan oleh Tuhannya. Setiap umat Hindu di Bali diwajibkan untuk mengetahui mantra ini.

Transmisi mantra Tri Sandhya mulai mengalami pergeseran pada saat ini. Hal ini dikarenakan beberapa faktor. Menurut beberapa pernyataan remaja Hindu Bali, faktor tersebut disebabkan karena kurangnya pengetahuan mengenai makna mantra, kurangnya pemahaman pentingnya manfaat dari mantra tersebut, kurangnya kesadaran dari tiap individu untuk mengamalkan mantra dan faktor lingkungan yang dapat mempengaruhi pola hidup mereka.

\section{Daftar Pustaka}

Ambarini \& Umaya. 2012. Semiotika, Teori dan Aplikasi pada Karya Sastra. Semarang: IKIP PGRI Semarang Press

Agustina, Lili. 2017. “Analisis Semiotik Dalam Kumpulan Cerpen Air Mata Ibuku dalam Semangkuk Sup Ayam" dalam Stilistika : Jurnal Bahasa, Sastra, dan Pengajarannya. Vol.2, No.1 : 54-63.

Ardiansyah, Rahmad Novianto. 2027. "Analisis Semiotika Riffaterre Pada Haiku Musim Panas Dalam Buku Oku No Hosomichi Karya Matsuo Basho" dalam Suar betang.vol.12, No.2 :173-182.

Dananjaya, S. 2013. Memuja Tuban dengan Puja Tri Sandhya Kramaning Sembah Ista Dewata Puja Kidung Dewa Yadnya dan Doa Metirtha Masekar, Mebija Dilengkapi dengan Sejarah Singkat Agama Hindu. Bandung: PT Dunia Pustaka Jaya.

Hamidin, Muhammad. 2016. "Bentuk, Fungsi, dan Makna Mantra Ritual Upacara Kasambu Masyarakat Muna di Kecamatan Katobu 
Kabupaten Muna" dalam Jurnal Bastra (Bahasa Sastra). Vol. 1, No. 2.

Https://KBBI.Web.Id/Transmisi.Html. Diakses pada tanggal 12 April 2018 pukul 10.00 .

Mantra dan Widiastuti. 2014. "Fungsi dan Makna Tradisi Lisan Genjek Kadong Iseng" Jurnal Bakti Saraswati. Vol. 03, No. 02.

Miharja, Deni. 2013. "Adat, Budaya dan Agama Lokal Studi Gerakan Ajeg Bali Agama Hindu Bali" dalam Jurnal Studi Agama dan Pemikiran Islam. Vol. 7, No. 1 : 55.

Nurjamilah, A. S. 2015. "Mantra Pengasihan: Telaah Struktur, Konteks Penuturan, Fungsi, dan Proses Pewarisannya" dalam Ejournal Riksa Bahasa. Vol. 1, No. 2.

Rukesi. 2017. "Nilai Budaya Dalam Mantra Bercocok Tanam Padi Di Desa Ronggo, Kecamatan Jaken, Kabupaten Pati, Jawa Tengah: Kajian Fungsi Sastra" dalam Jurnal Kajian Bahasa, Sastra Indonesia, dan Pembelajarannya. Vol.1, No.1 : 25-45.

Ratna, Nyoman Kutha. 2015. Teori Metode dan Teknik Penelitian sastra. Yogyakarta: Pustaka Pelajar.

Soegijono. 1993. "Wawancara Sebagai Salah Satu Metode Pengumpulan Data" dalam Media Litbangkes. Vol. 3, No. 1 : 17-21.

Saputra, Heru S.P. 2010. "Formula Dan Ekspresi Formulaik: Aspek Kelisanan Mantra dalam Pertunjukan Reog" dalam $\mathrm{Ma}$ kalah disetujui tanggal 5 oktober 2010. Hal 161-174

Tim Penyusun. 1998. Buku Pelajara Agama Hindu Untuk Siswa Sekolah Dasar Kelas III. Jakarta: Departemen Agama Hindu RI.

Tinarbuko, S.2003. "Semiotika Analisis Tanda Pada Karya Desain Komunikasi Visual" dalam Nirmana. Vol. 5, No. 1

Pradopo, R. D. 1999. "Semiotika: Teori, Metode, dan Penerapannya dalam Pemaknaan Sastra" dalam Humaniora. Volume 11, Nomor 1

Piliang, Y. A. 2004. "Semiotika Teks: Sebuah Pendekatan Analisis Teks" dalam Mediator.
Volume 5, Nomor 2

Waskita, Dana Dkk. 2011. "Sastra Lisan sebagai Kekuatan Kultural dalam Pengembangan Strategi Pertahanan Nasional di Pelabuhan Ratu Jawa Barat" dalam Jurnal sesioteknologi edisi 23. Diakses pada 16 maret 2018 pukul 21.00 .

Zulfadhli. 2010. "Mantra dalam Kesustraan Minangkabau dan Puisi-puisi Sutardji Calzoum Bachri : Suatu Analisa Sastra Bandingan" dalam Jurnal Bahasa dan Seni. Vol. 10 